\title{
Sílvio Coelho dos Santos
}

\author{
$* 1938$ \\ $+26.10 .2008$
}

$\mathrm{E}$ u era muito mais jovem que hoje quando travei conhecimento com o grande mestre Sílvio Coelho dos Santos - foi lá na altura em que começava a me preparar para construir um romance que depois se chamou "Cruzeiros do Sul", e eu precisava aprender um bocado sobre os antigos habitantes desta terra onde vivo, o povo que hoje chamamos de Xokleng. Estava assim bem perdida, sem saber por onde começar, quando me aconselharam a procurar o professor Sálvio Alexandre Muller, da Universidade local, que me recebeu com deferências que eu não imaginava:

- O que tu precisas conhecer é a pesquisa do Sílvio Coelho dos Santos!

Da sua biblioteca particular, Sálvio emprestou-me "Índios e brancos no sul do Brasil", exemplar tão manuseado que muitas folhas já estavam soltas, e quanto me lembro, como neste momento, que também o Sálvio já partiu, neste mesmo ano de 2008 ! É como se pedacinhos da gente fossem ficando ao longo da estrada, como se fôssemos sendo apedrejados pela vida!

Foi empunhando "Índios e brancos no sul do Brasil" que comecei a aprender sobre o Sílvio, a admirá-lo cada vez mais, quiçá mesmo a ter dele uma certa inveja, pois eu também queria ter podido viver a vida que ele viveu, experimentar as experiências que ele experimentou. Vim a conhecê-lo mais adiante; tornei-me sua confreira na Academia Catarinense de Letras; vi-o fazer fascinantes pronunciamentos e dar impressionantes conferências em tribunas universitárias; acabei ganhando dele o meu exemplar de "Índios e brancos no sul do Brasil"; a partir de algum momento tornamo-nos amigos; citei-o em diversos textos meus; trocávamos mensagens eletrônicas, e neste ano ele andou costurando para que eu fosse lançar meu livro "Sambaqui" lá na sede da ACL'.

No último final de semana fiquei a mandar-lhe mensagens, sem nem me passar pelo pensamento que, já suavemente impulsionado por dedicados anjos (diz-me o coração que entre eles estava o cacique Kam-Rem ${ }^{2}$ )

\footnotetext{
${ }^{1}$ ACL: Academia Catarinense de Letras

"Kam-Rem: cacique do povo Xokleng em 1914, à época da dita "pacificação" do mesmo.
} 


\section{Humanas}

que provavelmente provinham lá das gentes Xokleng, Sílvio já acenava em despedida, tomando o rumo de outras paragens, quem sabe uma etérea floresta subtropical com uma porção de pessoas precisando de ajuda!

Fica dificil, para mim, pensar que o Silvio se foi para sempre. Tento lembrá-lo como o ser humano extraordinário que era, lembrar das histórias que ouvi aqui e ali da boca dele, costurá-las numa biografia na forma como elas vêem à minha lembrança, trazer à tona o menino, o estudante, o homem, o cientista... Então acho que é bom começar da forma certa, pois certos seres só podem estar na nossa memória da forma mágica que lhes é devida, e então...

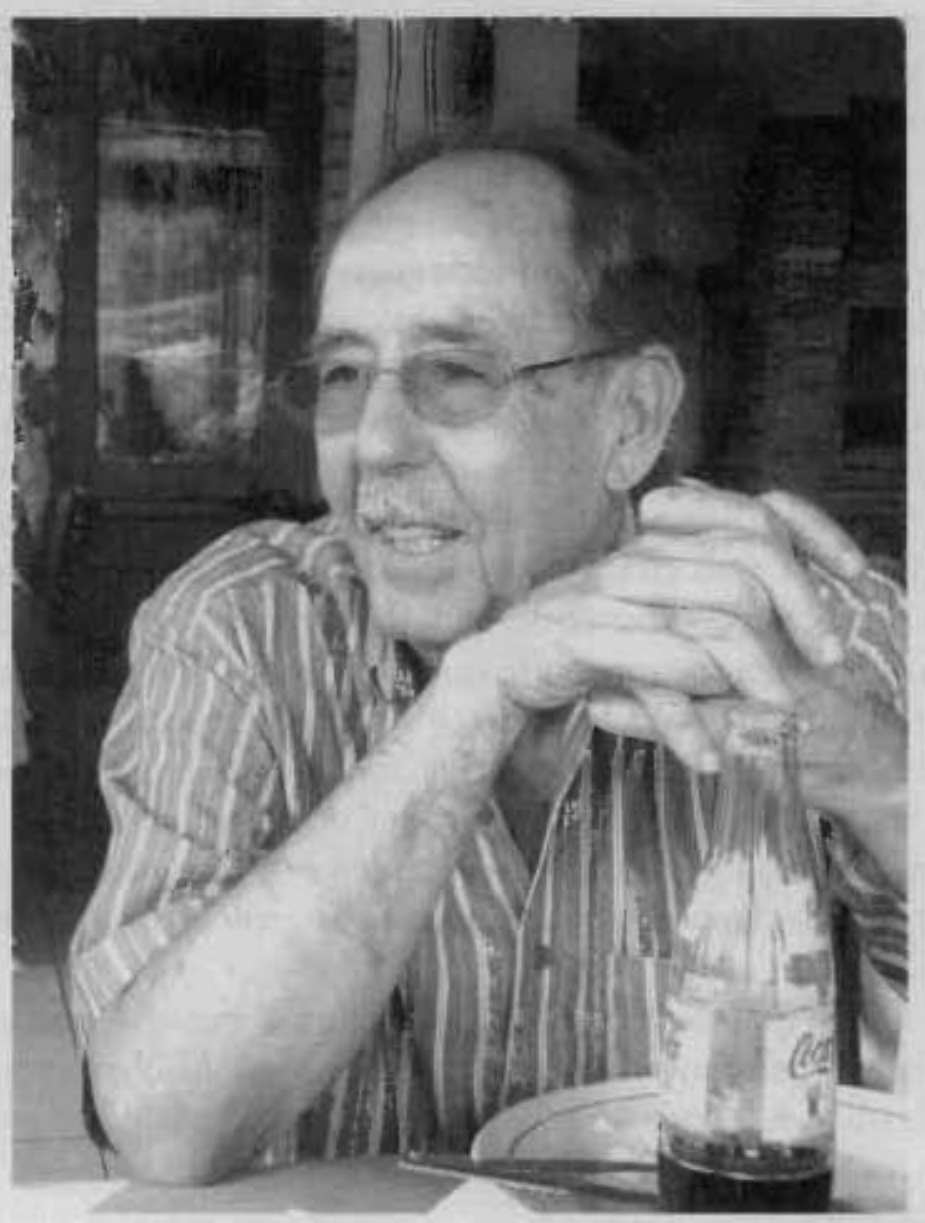

Figura 1

Silvio Coelho, almoço de fim de ano NEPI/PPGAS/UFSC, 2006 


\section{Era uma vez...}

Era uma vez um menino de Florianópolis ${ }^{3}$ que queria ser antropólogo, no tempo em que para se estudar Antropologia havia que ir-se ao Rio de Janeiro. Segundo Sílvio me contou, sua família não tinha as condições financeiras suficientes para tal, mas o que se fazer contra a força do Sonho? Ele teimou e teimou, e acabou no Rio de Janeiro, a estudar Antropologia, vivendo de forma humilde para poder se manter naquela cidade distante. Viajava para o sul nas férias, como as aves migram em certas estações, e embrenhava-se por estradas ainda não asfaltadas (estava-se na década de 1960) até a Reserva Indígena "Duque de Caxias", que então se situava no município de Ibirama/SC, e lá vivia com o povo Xokleng, férias após férias, ano após ano, tudo vendo, tudo aprendendo, tudo observando, tudo anotando. Há que se considerar que o Sílvio foi um felizardo: passou a conviver com aquele povo apenas cinqüenta anos depois do seu aldeamento, quando ainda estavam vivos muitos hábitos, costumes e tradições que talvez mais tarde tenham se extinguido. É esta a parte da vida dele que invejo: o que eu não daria para ter tido o mesmo privilégio! Tornar-se-ia, assim, ele, o maior estudioso e o maior especialista a respeito do povo Xokleng. Viria a estudar outros povos antigos, mais tarde, mas os Xokleng seriam sempre como que seus amigos maiores, e um dia o ouvi falar:

- Minha casa, em Florianópolis, funciona mais ou menos como uma embaixada Xokleng na capital... - pois seus amigos lá apareciam a cada vez que tinham que ir resolver alguma coisa com o governador, ou com a FU$\mathrm{NAI}^{4}$, ou qualquer outra autoridade. Pelo que entendi, nossos irmãos Xokleng tanto se hospedavam lá quanto contavam com a ajuda do influente antropólogo para as suas causas.

E aí me vem outro tipo de lembrança: Sílvio contando da sua estada no Rio, dos difíceis tempos de estudante:

- Nenhuma moça da universidade namoraria com um estudante de Antropologia. Todas elas só namoravam os rapazes da Medicina, ou da Engenharia, ou do Direito...

Penso agora naquelas moças todas que não quiseram namorar com o Sílvio e nos seus namorados da Medicina, da Engenharia e do Direito.

${ }^{3}$ Sul do Brasil

${ }^{4}$ FUNAl: Fundação Nacional do Índio 


\section{UMANÁ Cisn}

O que terá acontecido com aquela gente toda? Formaram-se, decerto; casaram-se, provavelmente; voltaram para as suas cidades e sumiram da história. Quem sabe deles? Não faço idéia. Do Sílvio, no entanto, muita gente soube por todo o mundo, e era ele que ia aos congressos internacionais, e era ele quem era chamado para as grandes conferências, e era ele quem escrevia livros brilhantes, e era ele alguém que eu gostaria de ter sido. E ele foi assim magnífico porque soube ser fiel aos seus sonhos, aos seus anseios, ao amor que nutria pela sua profissão e pela sua gente - que isto sirva de exemplo para cada um de nós; que isto sirva de exemplo para todos os outros que virão depois.

Então, era uma vez um menino de Florianópolis que segurou com a maior força dos seus pulsos os sonhos que tinha, e não se permitiu viver sem vivê-los, e então se tornou magnífico. Era uma vez um menino do sul do Brasil que aplicou as férias da sua juventude dentro de uma reserva indígena e abriu sua casa para que os irmãos originários tivessem uma embaixada na capital, e então se tornou inesquecível. Era uma vez um menino chamado Sílvio Coelho dos Santos que nos deixou para sempre, mas que se foi levado por Kam-Rem e tantos outros caciques que antes dele viraram anjo para os mais belos lugares de uma floresta encantada. Mais tarde irei encontrá-lo por lá, Sílvio, pois falta para minha vida viver um pouco como você viveu.

A gente se encontra, companheiro!

Blumenau, 28 de outubro de 2008.

UrdaAlice Klueger - Escritora 